\title{
Transforming Transition: enhancing practice in haemophilia
}

Sandra Dodgson, Mike Holland, Luke Pembroke, Kate Khair

Transition is the term used to describe the process of approaching and crossing the chronological boundary between paediatric and adult care services. Transfer of care describes the administrative arrangements associated with moving from a paediatric to an adult service across this boundary.

Transforming Transition was a nurse-led initiative designed to facilitate the sharing of knowledge and experience to enhance transition practice in the UK. The aims of the programme were to secure changes in working practices that enabled nurses to drive improved transition outcomes, enhance selfmanagement by people with haemophilia and develop clinical leadership. From the outset of the programme it was clear that there were differences in practice and that sharing practice would be one route to addressing some of these variations.

As a result of the knowledge and experience shared through the programme, resources described in this paper are available to all haemophilia centres. Sharing between people with haemophilia, their families

SANDRA DODGSON

Haemnet, London. Email: sandra@haemnet.com

MIKE HOLLAND

Haemnet, London. Email: mikeahaemnet.com

LUKE PEMBROKE

Haemnet, London. Email: luke@haemnet.com

KATE KHAIR

Haemnet, London. Email: kate@haemnet.com

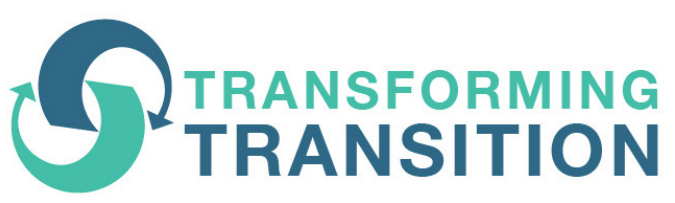

and carers, and the haemophilia clinical team have resulted in the development of practical resources that enhance practice within the haemophilia centre. Sharing of practice between nurses and young people with haemophilia at the programme workshops provided a focus for development of local and regional action plans, a framework for reviewing progress, the introduction of transition clinics and improved transition documentation.

Keywords: Transition, leadership, young people

$$
\begin{aligned}
& \text { he UK National Health Service (NHS) has } \\
& \text { chronological boundaries that inform } \\
& \text { the approach to care, including that } \\
& \text { received by young people with long-term }
\end{aligned}
$$
health conditions (LTHCS). The UK National Service Framework for children, young people and maternity services suggests that paediatric services should retain responsibility for young people until their sixteenth birthday, if not until they reach 18 years ${ }^{[1]}$. To many individuals this threshold is arbitrary. It does not take account of physical or mental health, developmental needs, social circumstances or life experiences. The process of approaching and crossing this service boundary is often described as transition. 
Transition is not the same for every illness or disorder or medical specialty; there are specific requirements depending on the impact of the disorder and the nature of the care provided. Much of the available information and support is generic, with transition support being designed to ensure that services are provided in a way that meets an individual's needs and assists the person, their family and carers throughout.

Transition is much more than the administrative arrangements associated with moving from a paediatric to an adult service: this transfer of care comprises changes in paperwork, facilitating the handover from one clinical team to another, and is only a part of the transition process. It is not a single event but a process lasting several years, and covers the way people, health professionals and health services work together.

Bleeding disorders are life-long conditions, often diagnosed in childhood by paediatric services. Bleeding disorders care in the UK is commissioned via specialised services and delivered through a network of designated haemophilia centres provided in paediatric, adult or combined treatment centres. While there is National Institute for Health and Care Excellence (NICE) guidance on transition from children's to adults' services for young people using health or social care services ${ }^{[2]}$, there is no haemophilia-specific national guidance about how or when transition planning should be implemented or what a successful outcome would be.

Within the haemophilia multidisciplinary team (MDT), specialist nurses often take the lead in working with individuals and their families to facilitate transition. A steering group of nurses working with young people with haemophilia came together to drive a programme entitled Transforming Transition. The programme was run by Haemnet, a haemophilia research, education and service development charity. It was funded through a competitively sought research grant within a transition theme from the Burdett Trust for Nursing, awarded in 2015. The goal was to enhance transition practice in the UK through providing opportunities to reflect on local practice and share approaches between participating centres. Outputs of the programme included greater understanding of transition, changes in practice and practical resources to facilitate patients' development of skills to self-treat and self-manage.

\section{What does the NHS mean by transition?}

Everyone who moves from a children's or young people's service to an adult service, whether they are receiving health or social care, should have a 'smooth transition to adult care for adolescents' as described by NHS England in the 2013/14 haemophilia service specification [3].

There has been a lot of research and debate about what constitutes an effective transition service [4-6]. In 2014, NICE developed an evidence-based guideline that could be applied in health and social care settings ${ }^{[2]}$. The learning from Phase 1 of the Transforming Transition programme was submitted to NICE as part of the consultation on this guideline.

The guideline applies to all services for young people, not only haemophilia. It is intended for everyone in health and social care involved in children's and adult health, mental health and social care services, others working with young people who use health and social care services (e.g. those working in education and employment agencies) and young people using heath or social care services who may need support from adults' services in the future, and their parents or carers. The guideline covers:

- Overarching principles for good transition

- Planning for transition

- Support before and after transfer

- The supporting infrastructure

An explanation of transition from the guideline is included in Box 1. The NICE guideline is not the only, or much less the last, word on designing transition, but the $\mathrm{NHS}$ and local authorities are expected to take it fully into account, alongside an individual's needs, preferences and values. There are many examples to draw on in the healthcare literature. A particular transition service may therefore not be organised exactly as the guideline suggests but would, after taking local circumstances into account, deliver what it recommends.

The NICE guideline states that the transition process should be person-centred:
"seeing the person using care and support as an individual and an equal partner who can make choices about their own care and support [...] to ensure that all of a young person's needs are supported, including those related to their wider context (for example, education and employment, community inclusion, health and wellbeing including emotional health, and independent living and housing options)." [2]

In addition, transition should be an active process that is purposeful and planned, and one that involves the person undergoing transition. It occurs at a time that is developmentally appropriate for the individual this means: 
Box 1. Transition from children's to adults' services for young people using health or social care ${ }^{[2]}$

The guideline published in 2016, explains transition as:

If you're a young person with health or social care needs, then as you get older there will come a time when you'll need to move from children's to adults' services. This is called a 'transfer'. It needs to be carefully planned so you feel prepared for the move and to make sure there are no gaps in the care you receive. It's important that you, and the people who support you, have enough time to really think about what types of care you'll need in the future.

After you transfer, adults' services should make sure that you have as much support and information as you need.

The period of planning, transfer, and the support you have afterwards is called 'transition'.

Transition doesn't start at the same age for everyone. It will depend on your care and support needs and what seems right for you. It will also depend on what the law says about different services.

The people who provide your care and support should involve you and your parents or carers at every stage of your transition. They should make sure you have the information you need to make decisions. The information should be easy for you to use and understand.

The guideline is supported by:

- A version written for patients and families/carers

- Tools and resources to help commissioners, professionals and practitioners with implementation

- Full details of the evidence that supports the guideline's recommendations

- A podcast (with transcript) of one person's experience of transition

- A quality standard, Transition from children's to adults' services (QS140), which provides a set of audit statements that commissioners, professionals and practitioners can use to assess how closely a transition process is aligned with the guideline ${ }^{[7]}$.

"An approach to supporting young people that recognises them as a distinct group, subject to constantly changing circumstances. Developmentally appropriate care and support considers the young person as a whole, addressing their biological, psychological and social development in the broadest terms. This approach will need joined-up service provision, and for the young person to be informed about, and supported to play an active role in, their care and support." [2]

It is, of course, important to audit local provisions for transition. Involvement in audit is a valuable learning exercise and something that all clinical staff should be part of. NICE has developed a Quality Standard to support performance monitoring of its transition guideline ${ }^{[7]}$. It consists of five statements on what the service will deliver, each of which has measurable endpoints:

- Young people who will move from children's to adults' services start planning their transition with health and social care practitioners by school year 9 (aged 13 to 14 years), or immediately if they enter children's services after school year 9 .
- Young people who will move from children's to adults' services have an annual meeting to review transition planning.

- Young people who are moving from children's to adults' services have a named worker to coordinate care and support before, during and after transfer.

- Young people who will move from children's to adults' services meet a practitioner from each adults' service they will move to before they transfer.

- Young people who have moved from children's to adults' services but do not attend their first meeting or appointment are contacted by adults' services and given further opportunities to engage.

The quality standard suggests measurable indicators and describes how they benefit the various stakeholders.

Services that incorporate this approach into a regular audit can utilise standard outcomes to share and learn from.

\section{Transforming Transition: sharing knowledge and experiences from practice}

Coming together to share knowledge and experience is an approach that is recognised as a route to enhancing 
practice. Interventions that facilitate the sharing of practice, such as action learning ${ }^{[8]}$, NHS quality, service improvement and design tools (QSIR) ${ }^{[9]}$, and communities of practice ${ }^{[10]}$ are used across the NHS. Transforming Transition was a nurse-led initiative designed to facilitate the sharing of transition practice. The aims of the programme were to secure changes in working practices that enable nurses to drive improved transition outcomes, enhance self-management by people with haemophilia and develop clinical leadership.

The programme involved a series of developmental workshops using action research ${ }^{[11]}$, in which nurses from more than 20 centres across the UK and Ireland came together to share practice and experience. The workshops were supplemented and informed by information gathering activities, through which patients' views of their transition experiences and nurses' views of their transition practice were captured ${ }^{[12,13]}$. Through these activities, a consensus view emerged that effective transition leads to better health outcomes (Figure 1).

From the outset of the programme it was clear that there were differences in practice and that sharing practice would be one route to addressing these variations. For many participants, the introduction of transition clinics and improved transition documentation resulted from the programme workshops. The workshops also provided a focus for the development of local and regional action plans, reviewing progress and developing next steps.

As a result of the knowledge and experience shared through the programme, resources available to all UK haemophilia centres include:

1. A statement describing what would be a successful outcome of transition

2. A framework for reviewing transition practice within haemophilia centres/networks

3. Transition resources for nurses and other members of the MDT; practical resources that can be used with young people, their carers and families (see below).

Defining successful outcomes of transition and transfer Achieving clarity with respect to what would be a successful outcome from the transition process and transfer to adult care services was recognised as being beneficial. The effectiveness or success of the overall transition process can be described in different ways. For example, a medical perspective might be to maintain treatment adherence with the least possible bleeding episodes; while an MDT perspective might be the least possible joint damage at transfer.
Throughout the programme, common themes emerged from the participants' discussions. These are captured in an overarching statement that provides a focus for haemophilia transition processes:

\section{"Transfer to adult services is significantly enhanced when people with haemophilia are able to self-infuse/self-treat and have been supported by their clinical team to understand and manage their condition (as developmentally appropriate)."}

This overarching aim aligns with the patient activation strand of the Five-Year Forward View for the NHS ${ }^{[14]}$, which sets out a central ambition for the NHS to become better at helping people with long-term conditions to manage their own health: staying healthy, making informed choices about treatment, managing conditions and avoiding complications. This statement also highlights two underpinning goals for transition practice, where possible:

- Young people learning to manage their haemophilia for themselves - that is, self-administer factor concentrates, identify and appropriately manage any bleeding episodes and manage the risks associated with everyday life

- The clinical team actively supporting individuals to learn to self-manage their haemophilia.

\section{Framework for reviewing transition practice} Long before NICE published its transition guideline, many NHS trusts and services had developed their own policies to support young people as they moved from paediatric to adult services in specialties such as diabetes and rheumatology, as well as haematology. These policies, many of which were considered in the development of the NICE guideline, are usually available from the websites of NHS trusts or their specialist services.

During the programme, participants saw the NICE guidance as providing a framework for reviewing practice and identifying areas of improvement. The indicators below, based on the NICE recommendations, were summarised for use by the programme participants to reflect on their transition practice. It is important to remember that this is derived from a guideline and is not an instruction manual; as such, it can readily be tailored to local need.

\section{Resources to support transition}

As a result of sharing experiences at the workshops and through additional activities led by programme 
participants, a number of transition resources were identified or developed through the programme. These resources are available for use by haemophilia centres across the UK; examples are shared below.

\section{Experience from other specialties:}

Ready Steady Go - Hello

Many NHS centres use the Ready Steady Go - Hello model ${ }^{[15,16]}$, which has been shown to be effective in supporting transition among people with other long-term conditions. Developed by Southampton University, this is a generic programme that provides a structured approach to transition for patients and their families/carers. The steps - Ready (from age 11), Steady (around age 13-14), Go (beginning at 16) and Hello (to adult services) - focus on finding out what individuals believe they can do, what they aspire to and how the service can respond.

It covers:

- Knowledge of condition (education/future)

- Self-advocacy - speaking up for yourself (psychosocial issues)

- Health and lifestyle (transition process)

It was felt that the advantage of Ready Steady Go Hello and similar initiatives is that they provide service users and health professionals with a clear way to engage with the transition process. It is a provider-led approach (in the sense that health professionals initiate the various steps) and recognises the importance of patients and families/carers being informed about the opportunities presented by transition, and feeling empowered to raise their own concerns and identify personal targets that can complement those of the structured programme.

Participating centres that were already using, or who became 'early adopters' during the programme, found this model valuable. It offers much that facilitates a transition service, notably a large variety of downloadable resources including information leaflets and questionnaires. The haemophilia nurses developed supplementary questions for using the tool with people with haemophilia (e.g. if the young person was able to self-infuse). It was agreed that this would be a much better use of resources than rewriting the tool so that it was haemophilia-specific.

Experiences of clinical colleagues: clinical leadership A core underpinning theme of the programme was clinical leadership. Nurses as members of the MDT working in partnership with their patients and families/ carers are well placed to lead changes in transition practice. In parallel with the Transforming Transition programme, development of haemophilia leadership was identified by the Haemophilia Nurse Association (HNA), resulting in development of the ASPIRE programme, co-funded by the HNA and Haemnet, with subsequent support from the pharmaceutical industry.

The ASPIRE programme has clinical leadership at its core ${ }^{[17]}$. It is open to haemophilia professionals from multiple disciplines, and is designed to support the development of leaders among members of the haemophilia care team in ways that contrasts with hierarchical leadership and management courses more typically found in the NHS. The programme aims to facilitate real-world change through sharing theoretical and practical perspectives on clinical leadership in haemophilia.

The non-clinical aspects of transition determine how a service is organised and run so that it can be effective and responsive. Good leadership is fundamental. Much of the development work to support patients and their families to prepare for transfer to adult services is provided by nurses. Strengthening their voices and those of their allied health professional colleagues in the MDT through developing skills and confidence is key to bringing about changes in transition practice within their centres.

Graduates of Haemnet's ASPIRE programme are already making a difference. One nurse secured responsibility for overall leadership of transition practice at her centre as a result of participating in ASPIRE and other initiatives to improve transition. Her colleagues on the programme supported her by sharing their local practice. She led the introduction of a transition clinic, initially for patients with severe haemophilia, which has improved both the patient experience and the centre's documentation. One of the objectives was to 'normalise' the opportunity for boys from the age of 11 to discuss issues with their clinical team without their parents by including this among the proposed changes to transition practice outlined in a letter sent to families and carers. A number of young people have since chosen to speak with members of their clinical team without a parent or carer present, and have welcomed the opportunity to do so.

Graduates from the ASPIRE programme have also used the knowledge and understanding of leadership gained to begin exploring, trialling and pioneering new approaches to transition in other centres. 
YOUNG PERSON AND THEIR

PARENTS/CARERS WORK

WITH THEIR CLINICAL TEAMS

IN PREPARATION FOR AND

DURING TRANSITION

(PERSON-CENTRED PLANNING)

LEADERSHIP

EDUCATION AND TRAINING

CONSENT AND

CONFIDENTIALITY
Management of transition is an active process:

- A named worker coordinates care around the individual and also provides support

- Plan early and prepare the young person and their parents/carers

- Provide a keyworker or lead professional to plan the transition with the young person - before and after transition

- Young people and their parents/carers are actively engaged in the management of their transition - this includes asking them if they feel that the transition delivered what they hoped and feeding back how their involvement has influenced the process

- Parents/carers are included and there is a planned and gradual transfer of responsibility for health to the young person (timing individualised)

- Staff from children's/young people's and adults' services are engaged in development of the plan

Transition planning:

- Identifies the hopes, aspirations and goals of the young person, who plays an active part in decisions about their future

- Is flexible in the timing of the move to adult services - the threshold is a demonstration of an adequate level of readiness for self-management

- Uses strategies to involve young people and parents/carers from isolated or hardto-reach communities

- Includes a review of the plan with the young person at least annually

- Provides support after transfer to the adult service

Include a health plan identifying the skills for self-management of their condition, which:

- Takes account of physical, psychological, social, educational and vocational aspects

- Addresses loss of continuity of care and ensures new relationships can be established

Effective leadership is in place throughout the organisation(s)

Child and adult teams are co-ordinated and knowledgeable

Young people and parents/carers are supported to build independence through:

- Being provided with knowledge about their condition and the skills and support to best manage their care

- Being taught self-infusion early

- Education and training being made available and accessed to develop the required competencies of all those delivering care (assess, plan, implement, evaluate and revise care according to all young people's and parents'/carers' individual needs)

- Ensuring good working knowledge of professional roles or the core team as well as other agencies

- Training professionals in adolescent health, and young people's developmental and wider social and emotional needs

- Offering contact with peer support groups

Confidentiality is maintained by all staff members.

Explicit or expressed valid consent is obtained and recorded prior to sharing information or providing treatment or care.

Local information-sharing protocols are observed, taking account of young people's wishes about confidentiality and the involvement of their parents/carers.

Young people's best interests are maintained where they lack the capacity to make particular decisions 
Clear, concise and consistent documentation that:

- Recognises and respects that the individual is a young person, not a child or adult

- Provides all relevant information to individuals and teams involved in supporting a young person's transition, including their GP, so they are able to liaise with other relevant teams to facilitate access to relevant services

- Is based on up-to-date evidence-based policies, procedures, protocols and guidelines

- Incorporates a health plan into each transition plan

- Provides accessible information about services, shares information between services and facilitates integrated working

Care records are clear, are maintained according to relevant guidance and subject to appropriate scrutiny

SERVICE PLANNING AND DELIVERY

SAFETY/SAFEGUARDING
Young people are engaged in the design and delivery of services, with opportunities to ask questions, express their opinions and make decisions.

Providers should review and redesign services to ensure they meet users' needs, including the use of technology and social media.

Services are designed to meet the differing needs of young people with severe haemophilia and other bleeding disorders, other non-severe bleeding disorders, girls with bleeding disorders and carrier girls.

Resources are targeted to deliver care

Care is integrated with:

- Collaborative and flexible working between teams and agencies

- Clear and effective communication between young people and parents/carers, staff, organisations and agencies

- A shared philosophy between adult and children's services, recognising cultural differences

- Co-ordinated, consistent and accessible links between health and social care organisations that work in partnership with other relevant agencies

Children's and adult services are engaged in identifying unmet need and strategic planning of services

All agencies working with young people and their families take all reasonable measures to ensure that the risks of harm to young people's welfare are minimised.

Safety and security of young people, parents/carers and staff is maintained at all times. Robust, integrated systems are in place to identify and respond to abuse, harm and neglect.

Assessment of readiness for transition

\section{Experiences from people with haemophilia: understanding the transition pathway}

Transfer from a paediatric service to an adult service begins somewhere around the age when a young person feels they are becoming more independent. This age is not fixed or the same for everyone - its timing depends on the views of the individual, their family or carers, and their healthcare providers. Likewise, there is no set duration or time limit to the transition process, because this also dependant on the views of those who are involved in the individualised process.
To enable programme participants to look at this overall process, the Transforming Transition programme supported a local workshop at which people with haemophilia, nurses and a psychologist described a person's journey from the time their haemophilia is diagnosed in infancy to becoming an adult, having a family and ageing (see Figure 1). They identified important life stages and examples of the emotional steps that individuals experience along the way. Moving through these stages from one to the next is central to the process of transition. 


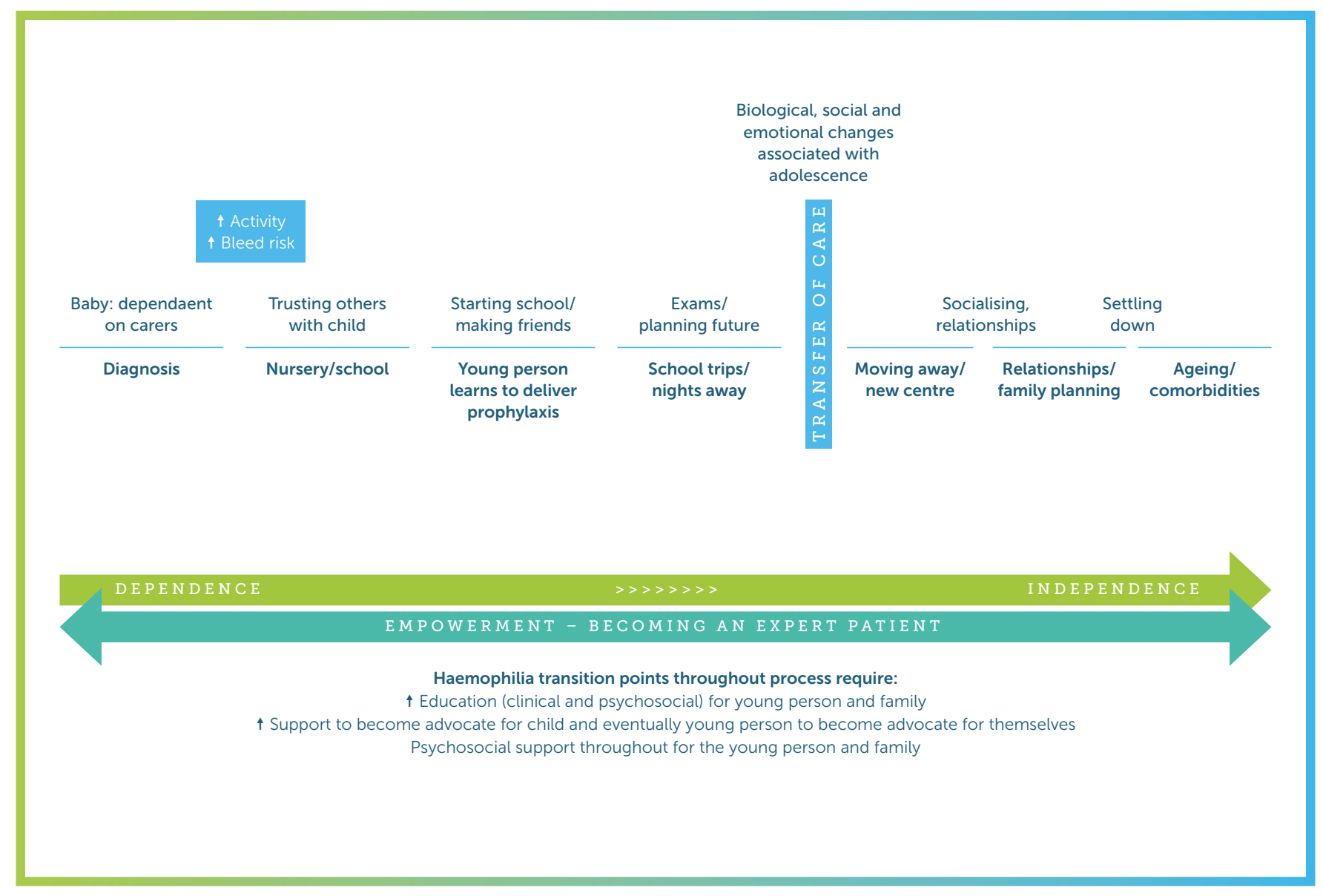

Figure 1. The lifelong transition pathway. (based on a Scottish haemophilia Network workshop supported by Haemnet. For further details please see O'Brien G, Hook S, Cossette N. Empowerment through transition - a qualitative exploration of young people's experiences. Poster presented at the World Federation of Haemophilia, Glasgow, May 2018.

This group agreed that a successful transition process could benefit from a more proactive approach. The participants agreed that earlier education around treatment and their options could make transition smoother.

\section{Experiences from people with haemophilia, their} families and carers: practical resources Haemnet has worked with people with haemophilia and nurses to develop practical resources for healthcare providers to use in engaging people with haemophilia in self-management.

One haemophilia centre worked with younger children to develop 'Haemic's Challenge', a mobile phone app that embedded learning about haemophilia within a fun game ${ }^{[18]}$. In clinic, boys are encouraged to play with the game while waiting to be seen. This experience is then used in the subsequent clinical consultation to underpin conversations about the individual's understanding of their haemophilia and treatment. This resource is now freely available to download for both Apple and Android phones.
Centres also worked with patients to develop educational videos and resources about the day-to-day issues of living with haemophilia from their perspective. All are freely available on Haemnet's YouTube channel ${ }^{[19]}$. They include:

- A video animation providing an overview of the transitions an individual with haemophilia will experience post-diagnosis. This animation is primarily aimed at carers and families, with the message that the person with haemophilia can live their life to the full with management of their haemophilia.

- A video animation focusing on self-infusion techniques. A workshop was held for young people working towards inserting the needle themselves, at which they shared knowledge of the stages in the process of self-infusion. Discussion was supported by their clinical nurse specialist and the young people were encouraged to share the hints and tips that they found useful. The process and hints and tips were captured and used to prepare short, sharable animations and files. 
- Other animations drawing on the experiences of people with haemophilia, their families and carers, working with members of the clinician team, have been developed. These explore topics such as how treatment works (pharmacokinetics), and support for individuals as they learn to self-treat and self-manage their haemophilia.

\section{Summary}

The Transforming Transitions programme demonstrated that it is possible to address some of the variations in practice through use of a service review tool based on NICE guidance, by sharing knowledge and experience of practice, and through support and challenge from colleagues.

Working with young people with haemophilia as peers within the programme had a significant impact on its outputs. The programme also highlighted that nurses are well placed to lead transition practice within haemophilia centres. Enhancing their influencing, service development and leadership skills would facilitate progress in this area.

Having a clearer sense of what a successful transition outcome would look like helps by providing a focus for development of local practice. The sharing of knowledge and experience between people with haemophilia, their carers and families and clinicians can be used to develop practical resources that facilitate the evolution of transition practice.

Overall, the programme indicates that developing the knowledge and skills to self-manage and live well with haemophilia in paediatric services can facilitate smooth transfer from paediatric to adult services.

\section{ACKNOWLEDGEMENTS}

The Transforming Transition programme was designed by Haemnet and funded by an educational grant from the Burdett Trust for Nursing.

This article does not contain any studies involving human participants or animals performed by any of the authors.

\section{REFERENCES}

1. Department of Health and Social Care. National service framework: children, young people and maternity services. 2004. Available at https://www.gov.uk/government/ publications/national-service-framework-children-youngpeople-and-maternity-services (accessed 19 October 2018)

2. National Institute for Health and Care Excellence. Transition from children's to adults' services for young people using health or social care services. NICE guideline [NG43], February 2016. Available at https://www.nice.org.uk/guidance/ng 43 (accessed 19 October 2018).
3. NHS England. 2013/14 NHS standard contract for haemophilia (all ages). B05/S/a. NHS Commissioning Board, 2013. Available at $h$ ttps://www.england.nhs.uk/wp-content/uploads/2013/06/ b05-haemophilia.pdf (accessed 19 October 2018).

4. Chaplin S. Transition from paediatric to adult services in haemophilia. J Haem Pract 2015; 2(2) : 1-2. doi:10.17225/ jhp00059

5. Waldboth V, Patch C, Mahrer-Imhof R, Metcalfe A. Living a normal life in an extraordinary way: A systematic review investigating experiences of families of young people's transition into adulthood when affected by a genetic and chronic childhood condition. Int J Nurs Stud 2016; 62: 44-59.

6. Gray WN, Schaefer MR, Resmini-Rawlinson A, Wagoner ST. Barriers to transition from pediatric to adult care: a systematic review. J Pediatr Psychol 2018; 43: 488-502.

7. National Institute for Health and Care Excellence. Transition from children's to adults' services. Quality standard [QS140]. 2016. Available at https://www.nice.org.uk/guidance/qs140/ chapter/Quality-statements (accessed 19 October 2018).

8. Revans RW. ABC of action learning. London: Routledge, 2011.

9. NHS Improvement. Quality, service improvement and redesign (QSIR) tools. 2018. Available at https://improvement.nhs.uk/ resources/quality-service-improvement-and-redesign-qsirtools/ (accessed 19 October 2018).

10. Lave J, Wegner E. Situated learning: legitimate peripheral participation (Learning in doing: social, cognitive and computational perspectives). Cambridge University Press, 1991.

11. Lewin K. Action research and minority problems. Journal of Social Issues 1946; 2(4): 34-46. doi: 10.1111/j.1540-4560.1946. tb02295.x.

12. Pembroke L, Dodgson S. Young people's experience of transition from paediatric to adult haemophilia care in the UK. J Haem Pract 2018; 5(1). doi: 10.17225/jhp00127.

13. Holland M, Dodgson S, Chaplin S. Steps to transition. J Haem Pract [forthcoming, 2019].

14. NHS England. NHS Five Year Forward View. Available at https://www.england.nhs.uk/five-year-forward-view/ (accessed 19 October 2018).

15. Southampton Children's Hospital. Transition to adult care: Ready Steady Go. Available at $h t t p: / /$ www.uhs.nhs.uk/OurServices/Childhealth/ TransitiontoadultcareReadySteadyGo/Transitiontoadultcare. aspx (accessed19 October 2018).

16. Nagra A, McGinnity PM, Davis N, Salmon AP. Implementing transition: Ready Steady Go. Arch Dis Child Educ Pract Ed 2015; 100: 313-20. doi:10.1136/archdischild-2014-307423.

17. Dodgson S, Bryan J, Fletcher S, et al. Aspire. Empowering professionals to lead haemophilia care. J Haem Pract 2018; 4(1): 22-8. doi: 10.17225/jhp00103.

18. Cardiff and Vale Local University Health Board. Haemic's Challenge. Available at https://appadvice.com/app/haemicschallenge/1386230816 (accessed 19 October2018).

19. Haemnet YouTube channel. Available at www.youtube.com/ channel/UCHd_8Js_-MB78TsFbmOSV_g (accessed 19 October 2018). 


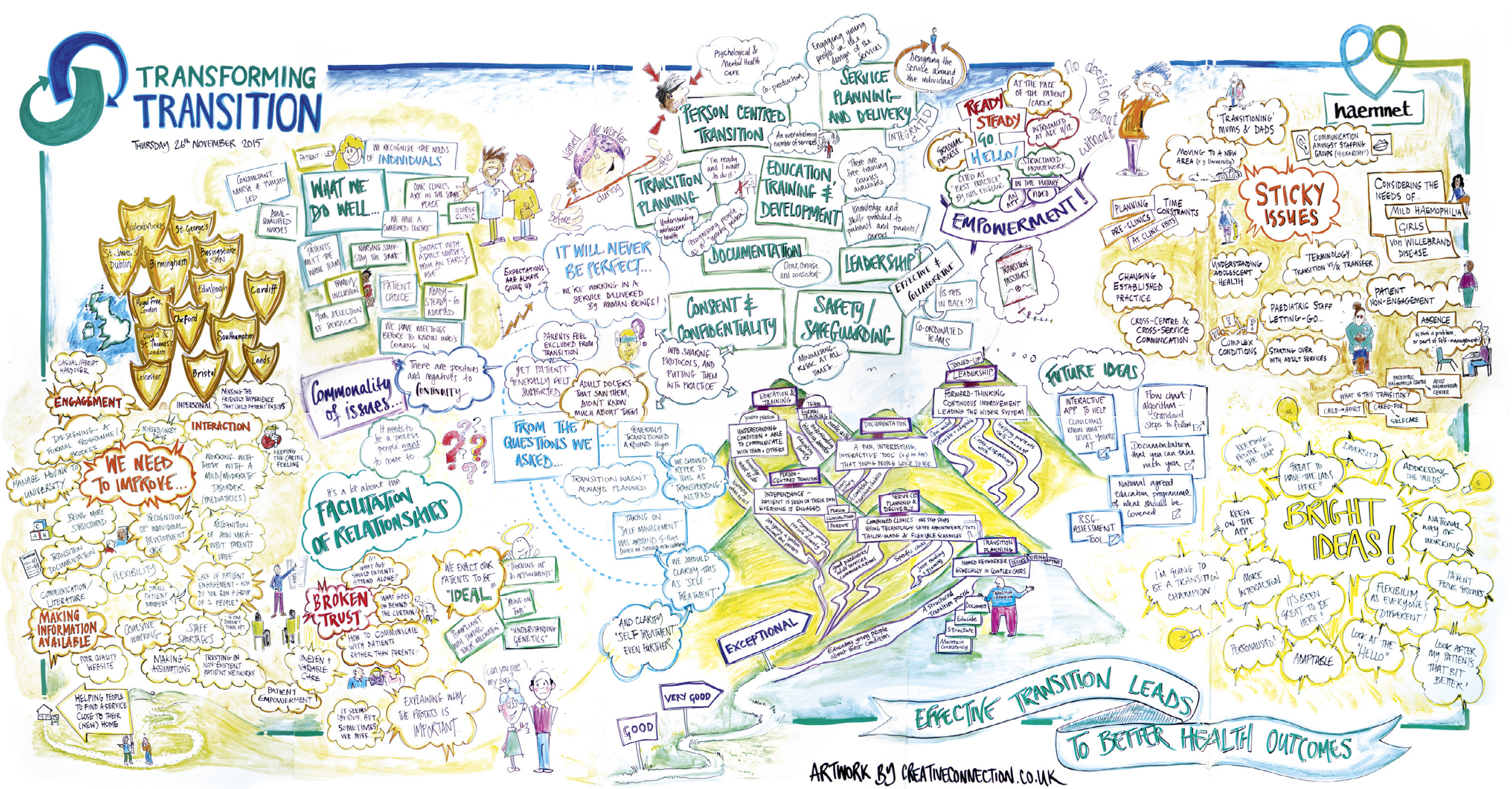

Figure 2: Views expressed in the workshops were captured graphically 


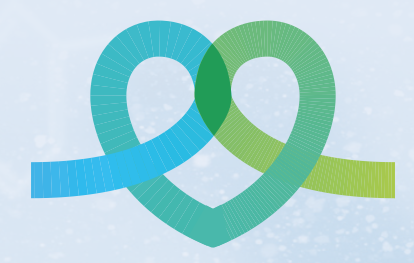

\section{The Journal of Haemophilia Practice}

An open-access journal for sharing experience in the care of people with bleeding disorders 